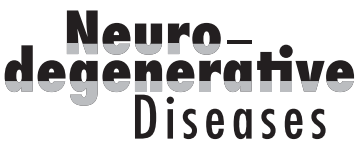

\title{
Direct Evidence for Self-Propagation of Different Amyloid- $\beta$ Fibril Conformations
}

\author{
Thomas Spirig Oxana Ovchinnikova Toni Vagt Rudi Glockshuber \\ Department of Biology, Institute of Molecular Biology and Biophysics, ETH Zurich, Zurich, Switzerland
}

\author{
Key Words \\ Alzheimer's disease · Thioflavin T · Electron microscopy · \\ Aggregation · Prion
}

\begin{abstract}
Background: Amyloid fibrils formed by amyloid- $\beta$ (A $\beta$ ) peptides are associated with Alzheimer's disease and can occur in a range of distinct morphologies that are not uniquely determined by the $A \beta$ sequence. Whether distinct conformations of $A \beta$ fibrils can be stably propagated over multiple cycles of seeding and fibril growth has not been established experimentally. Objective: The ability of the 40-residue peptide $A \beta_{1-40}$ to assemble into fibrils with the conformation of the mutant $A \beta_{1-40}$ peptide containing the 'Osaka' mutation E22 $\Delta$ was investigated. Methods: Fibril formation of highly pure, recombinant $A \beta_{1-40}$ in the presence of distinct, preformed seeds in vitro was recorded with thioflavin T fluorescence, and distinct fibrillar structures were identified and distinguished by fluorescence spectroscopy and electron microscopy. Results: We propagated the specific quaternary structure of $A \beta_{1-40} E 22 \Delta$ fibrils with wild-type $A \beta_{1-40}$ over up to seven cycles of seeding and fibril elongation. As a result of a $10^{7}$-fold dilution of the initially present $A \beta_{1-40} E 22 \Delta$ seeds, the vast majority of fibrils formed after the seventh propagation cycle with $A \beta_{1-40}$ did not contain a single molecule of $A \beta_{1-40} E 22 \Delta$, but still retained the conformation of the initial $A \beta_{1-40} E 22 \Delta$ seeds. Increased critical concentrations of $A \beta_{1-40}$ fibrils formed in the presence of $A \beta_{1-40} E 22 \Delta$ nuclei suggest that these fibrils are less stable than homolo-
\end{abstract}

\begin{tabular}{ll}
\hline KARGER & $\begin{array}{l}\text { ( } 2014 \text { S. Karger AG, Basel } \\
1660-2854 / 14 / 0143-0151 \$ 39.50 / 0\end{array}$ \\
E-Mail karger@karger.com & $\begin{array}{l}\text { This is an Open Access article licensed under the terms of the } \\
\text { www.karger.com/ndd }\end{array}$ \\
$\begin{array}{l}\text { Creative Commons Attribution-NonCommercial 3.0 Un- } \\
\text { ported license (CC BY-NC) (www.karger.com/OA-license), } \\
\text { applicable to the online version of the article only. Distribu- } \\
\text { tion permitted for non-commercial purposes only. }\end{array}$
\end{tabular}

gously seeded $A \beta_{1-40}$ fibrils, consistent with a kinetically controlled mechanism of fibril formation. Conclusion: The propagation of a distinct $A \beta$ fibril conformation over multiple $c y$ cles of seeded fibril growth demonstrates the basic ability of the $A \beta$ peptide to form amyloid strains that in turn may cause phenotypes in Alzheimer's disease.

(c) 2014 S. Karger AG, Basel

\section{Introduction}

The formation and deposition of abnormally aggregated proteins has been implicated in various neurodegenerative disorders, including Alzheimer's disease (AD), Parkinson's disease, Huntington disease and spongiform encephalopathies [1]. The highly stable protein aggregates known as amyloid fibrils are characterized by the presence of an ordered $\beta$-sheet structure and a unique fibrous appearance [2]. There is a continuous debate regarding the destructive versus protective effect of such protein aggregates. The abnormal accumulation of fibrillar protein aggregates, however, appears to be a common feature of many progressive neurodegenerative diseases $[3,4]$. Moreover, the ability to form amyloid fibrils is not limited to a specific set of proteins involved in disease, but appears to be a common property of any polypeptide under appropriate conditions [5-7].

Amyloid- $\beta$ (A $\beta)$ peptides are the main component of neuritic plaques present in individuals suffering from $\mathrm{AD}$, the most prevalent neurodegenerative disease in el- 
derly people [8]. A $\beta$ is formed by endoproteolytic cleavage of the $\beta$-amyloid precursor protein. Alternative cleavage of this protein results in various $A \beta$ isoforms, of which $A \beta_{1-40}$ represents the major isoform in the human brain [9]. While increasing age is considered to be the greatest $\mathrm{AD}$ risk factor, a small number of $\mathrm{AD}$ cases have a familial background. Familial AD can be associated with mutations in the $A \beta$ sequence such as the deletion of glutamate 22 ('Osaka' mutation) identified in Japanese patients [10]. $\mathrm{A} \beta_{1-40} \mathrm{E} 22 \Delta$ forms amyloid fibrils with a unique quaternary structure distinct from wild-type (WT) fibrils, shows an increased tendency to form fibrillar bundles and is more toxic than WT $A \beta_{1-40}$, possibly explaining the early onset of $\mathrm{AD}$ symptoms associated with this mutation [11, 12].

The molecular pathway of $A \beta$ fibril formation is still not completely understood, in particular because the isolation and characterization of intermediates has proven to be very challenging. It is, however, widely accepted that fibrillization follows a nucleation-dependent polymerization mechanism, which requires the formation of an ordered fibrillar nucleus (seed) followed by fibril elongation through the incorporation of additional $A \beta$ monomers [13-15]. The formation of nuclei with seeding activity represents the rate-limiting step in $A \beta$ fibrillization and typically results in a lag phase in fibril growth, which can be eliminated by the addition of preformed seeds [16]. Solid-state nuclear magnetic resonance combined with mutational analysis has recently provided detailed insight into the three-dimensional structures of a multitude of polymorphs of $A \beta$ fibrils, which usually form parallel $\beta$-sheet structures along the fibril axis $[17,18]$. A $\beta$ fibrils formed by the same peptide can occur in a range of structurally different morphologies. Depending on the experimental conditions, $A \beta_{1-40}$ can adopt a variety of distinct fibril structures in vitro [19-22]. Notably, the conformational variability of protein aggregates has also been implicated in prion diseases. The existence of prion strains with distinct phenotypes can be explained by several different, self-propagating conformations of prion protein fibrils [23]. Whether conformational strains resulting in distinct disease phenotypes also exist in $\mathrm{AD}$ and $\mathrm{A} \beta$ amyloids behave like an infectious agent remains a matter of debate [24-28]. Studies with transgenic mice demonstrated that in vivo seeding of $A \beta$ can induce amyloid formation and generate distinct phenotypes depending on the injected amyloid agent [29-32]. Recently, distinct fibril conformations of tissue-derived $A \beta_{1-40}$ from patients with different clinical histories suggested that variations in fibril structures might correlate with variations in $\mathrm{AD}$ development [33]. In vitro seeding experiments indicated that $\mathrm{A} \beta$ fibrils can adopt distinct conformational properties from their seeds [11,34-36]. However, repeated selfpropagation of distinct $A \beta$ fibrils retaining their specific quaternary structure, which is the basis for possible strain phenomena in $\mathrm{AD}$, has not been reported so far for $\mathrm{A} \beta$ peptides. Here, we show that specific conformations of $\mathrm{A} \beta_{1-40}$ fibrils can be propagated over multiple cycles of seeding and fibril elongation. The data provide a molecular basis for the existence of strains in $\mathrm{AD}$ and contribute to a mechanistic understanding of $A \beta$ fibril formation.

\section{Materials and Methods}

Preparation of Recombinant $A \beta_{1-40}$

The plasmids for the expression of $A \beta_{1-40} \mathrm{WT}$ and $\mathrm{A} \beta_{1-40} \mathrm{E} 22 \Delta$ as fusions to the peptide sequence (NANP) ${ }_{19}$ with an N-terminal (His) ${ }_{6}$ tag have been described previously $[12,37]$. The fusion proteins were expressed in Escherichia coli BL21 (DE3) cells (New England BioLabs) under T7 promoter control in Terrific Broth medium containing $0.1 \mathrm{mg} / \mathrm{ml}$ ampicillin. Protein expression was induced with $1 \mathrm{mM}$ IPTG for $4 \mathrm{~h}$ at $37^{\circ} \mathrm{C}$. The $\mathrm{A} \beta$ fusions were purified and cleaved with tobacco etch virus protease, and the resulting A $\beta$ peptides were purified by reverse-phase HPLC as described [12]. The purity and identity of the $A \beta$ preparations were verified by analytical reverse-phase HPLC on a Zorbax SB300 C8 column (Agilent) and matrix-assisted laser desorption ionization time-of-flight mass spectrometry, respectively (data not shown). Pure peptides were aliquoted in Protein LoBind Eppendorf tubes (Vadaux-Eppendorf), lyophilized and stored at $-80^{\circ} \mathrm{C}$.

\section{Fibril Growth}

Solutions of $A \beta_{1-40}$ WT and $A \beta_{1-40}$ E22 $\Delta$ monomers were prepared by dissolving the lyophilized $A \beta$ peptides in $10 \mathrm{~mm} \mathrm{NaOH}$ followed by ultracentrifugation $\left(135,500 \mathrm{~g}, 1 \mathrm{~h}, 4^{\circ} \mathrm{C}\right)$ to remove any residual aggregates. The soluble $A \beta$ monomers in the supernatant were carefully removed and their concentration determined via the specific absorbance of $A \beta$ at $280 \mathrm{~nm}\left(1,730 \mathrm{M}^{-1} \mathrm{~cm}^{-1}\right)$. $\mathrm{A} \beta$ monomer stock solutions were generated by dilution of the peptides to a concentration of $100 \mu \mathrm{M}$ in $10 \mathrm{mM} \mathrm{NaOH}$. The $\mathrm{A} \beta$ fibrils were formed at $25^{\circ} \mathrm{C}$ with shaking in a volume of $150 \mu \mathrm{l}$ in a black 96-well plate with a clear bottom (Greiner Bio-One) sealed with a VIEWseal foil (Greiner Bio-One) to prevent evaporation in a microtiter plate reader (BioTek Instruments). The fibrillization reactions were initiated by dilution of the $A \beta$ stock solution to a final concentration of $10 \mu \mathrm{M} \mathrm{A} \beta$ peptide in aggregation buffer $\left(10 \mathrm{mM} \mathrm{H}_{3} \mathrm{PO}_{4}-\mathrm{NaOH} \mathrm{pH} 7.4,100 \mathrm{mM} \mathrm{NaCl}, 35 \mu \mathrm{M}\right.$ thioflavin $\mathrm{T}(\mathrm{ThT})$ ). Fibril formation was followed by monitoring ThT fluorescence using wavelengths of $440 \pm 15$ and $485 \pm 10 \mathrm{~nm}$ for excitation and emission, respectively. All fibrillization curves represent the average of three replicate wells.

\section{Seeding Experiments}

To generate seeds for subsequent fibrillization reactions, fibrils were collected after completion of the assembly reaction and sonicated for $12 \mathrm{~min}$ at $4^{\circ} \mathrm{C}$ in a water bath-based sonicator (Bandelin 
Electronic). The kinetics of ThT fluorescence change for $A \beta_{1-40}$ WT were followed in the presence of seeds from sonicated $A \beta_{1-40}$ WT or $A \beta_{1-40}$ E22 $\Delta$ fibrils. All seeding experiments were performed with $10 \%$ of freshly prepared seeds and $90 \%$ of soluble $A \beta$ monomer, resulting in a total $A \beta$ concentration of $10 \mu \mathrm{M}$. The reactions were otherwise performed under the conditions described above for spontaneous fibrillization reactions.

\section{ThT Fluorescence Spectra}

The fluorescence spectra of aliquots of the $A \beta_{1-40}$ aggregation reactions were measured after maximum ThT fluorescence had been reached. The spectra were recorded on a QuantaMaster fluorescence spectrometer (QM-7/2003; Photon Technology International) in the range of $450-550 \mathrm{~nm}$ (excitation at $440 \mathrm{~nm}$ ) and corrected for the buffer.

\section{Electron Microscopy}

Samples for transmission electron microscopy were removed from the aggregation reactions after the maximum ThT fluorescence had been reached. The fibril suspensions were applied to carbon-coated copper grids (Quantifoil Micro Tools) for $1 \mathrm{~min}$ and stained with $2 \%(\mathrm{w} / \mathrm{v})$ uranyl acetate for $30 \mathrm{~s}$. Electron micrographs were recorded at $100 \mathrm{MeV}$ on an FEI Morgagni 268 transmission electron microscope.

\section{Critical Concentrations}

Aliquots were removed from fibrillization reactions $12 \mathrm{~h}$ after a constant plateau in ThT fluorescence had been reached and subjected to ultracentrifugation $\left(135,500 \mathrm{~g}, 20 \mathrm{~min}, 25^{\circ} \mathrm{C}\right)$ in order to precipitate formed fibrils. The concentration of the soluble $\mathrm{A} \beta$ monomers in the supernatants was then determined using an $\mathrm{A} \beta_{1-40}$-specific quantitative enzyme-linked immunosorbent assay (ELISA). Appropriate dilutions of the supernatants were incubated in high-binding polystyrene 96-well microplates (Greiner BioOne) for $2 \mathrm{~h}$ at room temperature to allow binding of $\mathrm{A} \beta$ monomers to the wells. After blocking with $200 \mu \mathrm{l}$ of $2 \%$ bovine serum albumin in PBS overnight at $4^{\circ} \mathrm{C}$, rabbit anti- $\beta$-amyloid $1-40$ antibody $(0.1 \mu \mathrm{g} / \mathrm{ml}$; Merck Millipore) in $100 \mu \mathrm{l}$ of blocking buffer was added and incubated for $2 \mathrm{~h}$ at room temperature, followed by the addition of $100 \mu \mathrm{l}$ of horseradish peroxidase-conjugated antirabbit IgG antibody $(0.27 \mu \mathrm{g} / \mathrm{ml}$; Merck Millipore $)$ in blocking buffer as a secondary antibody. After incubation for $2 \mathrm{~h}$ at room temperature, the antibody-bound $A \beta$ was visualized by the addition of

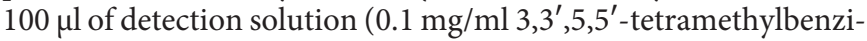
dine, $0.01 \%(\mathrm{v} / \mathrm{v}) \mathrm{H}_{2} \mathrm{O}_{2}, 0.1 \mathrm{M}$ acetic acid- $\mathrm{NaOH}$ pH 6.0). The reaction was stopped with $2 \mathrm{M} \mathrm{H}_{2} \mathrm{SO}_{4}(100 \mu \mathrm{l})$ and the absorbance at $450 \mathrm{~nm}$ was determined using a microtiter plate reader (BioTek Instruments). After each step the wells were washed 3 times with $250 \mu \mathrm{l}$ PBS $+0.05 \%(\mathrm{v} / \mathrm{v})$ Tween 20 . As a reference for quantification, standard curves for $\mathrm{A} \beta_{1-40} \mathrm{WT}$ and $\mathrm{A} \beta_{1-40} \mathrm{E} 22 \Delta$ monomers were established (online suppl. fig. S1; for all online suppl. material, see www.karger.com/doi/10.1159/000363623). Samples with known concentrations $(0.5-10 \mathrm{nM})$ of soluble $\mathrm{A} \beta_{1-40} \mathrm{WT}$ or $\mathrm{A} \beta_{1-40}$ E22 $\Delta$ were generated from $A \beta$ stock solutions $(100 \mu \mathrm{M})$ by serial dilutions in $0.2 \mathrm{M} \mathrm{Na}_{2} \mathrm{CO}_{3} / \mathrm{NaHCO}_{3} \mathrm{pH}$ 9.5. The absorbance at $450 \mathrm{~nm}$ was then plotted against the $\mathrm{A} \beta$ concentration, and the standard curves were fitted empirically with a 4-parameter sigmoidal model.

The apparent free energies of fibril elongation/dissociation $\left(\Delta \mathrm{G}^{\mathrm{app}}\right)$ were calculated according to the equation $\Delta \mathrm{G}^{\mathrm{app}}=-\mathrm{RT} \ln$

Self-Propagation of A $\beta$ Fibril

Conformations $\left(1 / C_{r}\right)$, as the critical concentration $\left(C_{r}\right)$ is the inverse of the amyloid fibril growth equilibrium constant under the assumption that the molar concentration of growing ends does not change as monomers associate to and dissociate from the ends of the fibrils in a dynamic equilibrium $[16,38,39]$.

\section{Results}

\section{$A \beta_{1-40}$ Can Be Efficiently Seeded to Form Distinct}

\section{Fibril Structures}

Fibril formation of $A \beta_{1-40}$ and the mutant peptide $\mathrm{A} \beta_{1-40} \mathrm{E} 22 \Delta\left(\mathrm{pH} 7.4,25^{\circ} \mathrm{C}\right)$ and initial $\mathrm{A} \beta$ monomer concentrations of $10 \mu \mathrm{M}$ was followed in a microtiter plate reader monitoring the fluorescence increase of the amyloid-specific dye ThT. As recently demonstrated for aggregation reactions under similar conditions, $A \beta_{1-40}$ E22 $\Delta$ fibrils adopted a quaternary structure distinct from that of $A \beta_{1-40}$ WT fibrils (fig. 1a) [12]. Characteristic properties of these $A \beta_{1-40}$ E22 $\Delta$ fibrils include about a 5 -fold higher specific ThT fluorescence intensity and a shift in the ThT fluorescence emission maximum from 485 to $474 \mathrm{~nm}$ (fig. 2), which allowed us to follow the propagation of this specific fibril conformation in crossseeded fibrillization reactions in quantitative terms. Fibrils of $A \beta_{1-40}$ WT and $A \beta_{1-40}$ E22 $\Delta$ were sonicated to produce smaller fragments, which were used to seed subsequent fibril formation. We analyzed aggregation kinetics of $\mathrm{A} \beta_{1-40}$ WT in the presence of $10 \%$ of preformed $\mathrm{A} \beta_{1-40}$ WT seeds (homologous seeding) and in the presence of $10 \%$ of $A \beta_{1-40}$ E22 $\Delta$ seeds (heterologous seeding or cross-seeding). As expected, a lag phase in the aggregation kinetics of $A \beta_{1-40}$ WT was no longer observable when seeded with $A \beta_{1-40}$ WT fibrils (fig. 1b). Aggregation of $\mathrm{A} \beta_{1-40}$ WT was also accelerated when cross-seeded with $\mathrm{A} \beta_{1-40}$ E22 $\Delta$ fibrils, indicating coaggregation of $A \beta_{1-40}$ WT with preformed fibrils of $A \beta_{1-40}$ E22 $\Delta$ (fig. 1b). Importantly, the ThT fluorescence intensity reached the high values characteristic for $A \beta_{1-40} E 22 \Delta$ fibrils, suggesting that the new fibrils formed from $\mathrm{A} \beta_{1-40} \mathrm{WT}$ adopted the conformation of the E22 $\Delta$ nuclei. The final ThT fluorescence value for the cross-seeded reaction was slightly higher compared to the unseeded $\mathrm{A} \beta_{1-40}$ E22 $\Delta$ fibrillization reaction, possibly due to larger amounts of wellstructured fibrils and a smaller percentage of amorphous $\mathrm{A} \beta_{1-40}$ aggregates. In contrast to $\mathrm{A} \beta_{1-40} \mathrm{WT}$ cross-seeded with $A \beta_{1-40}$ E22 $\Delta$ seeds, $A \beta_{1-40}$ E22 $\Delta$ monomers were not efficiently seeded by $A \beta_{1-40}$ WT nuclei, which was manifested by the presence of a lag phase and final ThT fluorescence levels specific for $\mathrm{A} \beta_{1-40}$ E22 $\Delta$ fibrils (data not shown). 


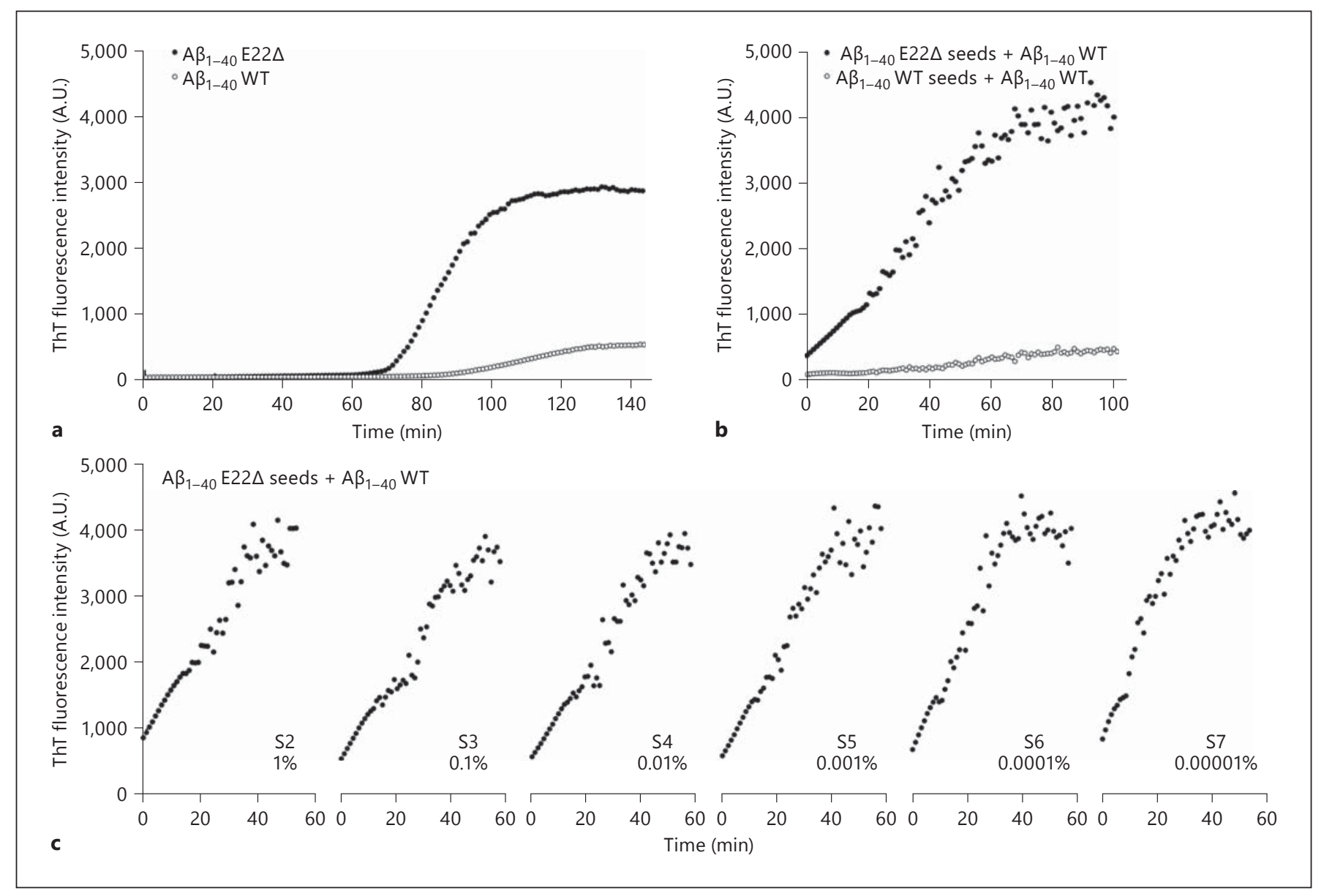

Fig. 1. Kinetics of seeded fibril formation of recombinant $A \beta_{1-40}$ in vitro at $\mathrm{pH} 7.4$ and $25^{\circ} \mathrm{C}$, monitored by ThT fluorescence. a Aggregation of $\mathrm{A} \beta_{1-40} \mathrm{WT}$ and $\mathrm{A} \beta_{1-40} \mathrm{E} 22 \Delta$ in the absence of seeds. The increase in ThT fluorescence at $485 \mathrm{~nm}$ is shown for reactions with initial concentrations of $10 \mu \mathrm{M}$ of recombinant $\mathrm{A} \beta$ peptide. $\mathbf{b}$ Kinetics of ThT fluorescence for A $\beta_{1-40}$ WT in the presence of $10 \%$ seeds from sonicated $A \beta_{1-40}$ WT or $A \beta_{1-40}$ E22 $\Delta$ fibrils. c Kinetics of ThT fluorescence for multiple seeding/propagation rounds of

\section{Self-Propagation of $A \beta_{1-40}$ Fibril Conformations Can} Be Followed over Multiple Seeding Cycles

To our knowledge, repeated seeding over more than two cycles with the retention of a specific fibril conformation has not been demonstrated experimentally for $A \beta$ fibril propagation in vitro. To test whether $A \beta$ can stably propagate a specific quaternary structure in a prion-like fashion, we followed the kinetics of multiple seeding cycles in which newly formed fibrils of $A \beta_{1-40}$ WT, initially seeded with fibrillar $A \beta_{1-40}$ E22 $\Delta$ nuclei, were used as seeds in successive aggregation reactions with fresh preparations of monomeric $\mathrm{A} \beta_{1-40} \mathrm{WT}$. We observed that the increased ThT fluorescence levels of
$\mathrm{A} \beta_{1-40} \mathrm{WT}$, where only the first fibrillization reaction contained seeds from $A \beta_{1-40}$ E22 $\Delta$ fibrils. Seeding cycles were repeated 7 times - each time by mixing $10 \%$ seeds from freshly formed fibrils with $90 \%$ monomeric $A \beta_{1-40}$ WT to a total $A \beta$ concentration of $10 \mu \mathrm{M}$. The seeding cycle number (S2-S7) and the relative amount of $\mathrm{A} \beta_{1-40} \mathrm{E} 22 \Delta$ present in the respective fibrillization reaction are indicated.

the cross-seeded fibrils were preserved and transmitted during seven seeding cycles (fig. 1c). Moreover, all fibrils formed during these multiple seeding cycles also displayed ThT fluorescence emission spectra almost identical to those of pure $A \beta_{1-40}$ E22 $\Delta$ fibrils, with a characteristic shift of the emission maximum from 485 to $474 \mathrm{~nm}$ compared to $A \beta_{1-40} \mathrm{WT}$ (fig. 2). These results indicate that seven generations of fibrils of $A \beta_{1-40}$ WT initially seeded with $\mathrm{A} \beta_{1-40} \mathrm{E} 22 \Delta$ nuclei adopt a quaternary structure similar to the $A \beta_{1-40}$ E22 $\Delta$ seeds. To confirm that specific conformational properties of $A \beta_{1-40}$ E22 $\Delta$ seeds are propagated with $\mathrm{A} \beta_{1-40} \mathrm{WT}$, we examined the morphologies offormed fibrils by electron microscopy (fig. 3). 
Fig. 2. ThT fluorescence emission spectra of $A \beta_{1-40}$ WT fibrils and fibrils of $A \beta_{1-40}$ WT initially seeded with $A \beta_{1-40}$ E22 $\Delta$ fibrils after each seeding/propagation reaction (the seeding cycle numbers $\mathrm{S} 1-\mathrm{S} 7$ are indicated). Fluorescence emission spectra of fibril-bound ThT for $\mathrm{A} \beta_{1-40} \mathrm{WT}, \mathrm{A} \beta_{1-40}$ E22 $\Delta$ and fibrils from the seeding experiments in figure 1 are shown. The spectra were normalized to the respective fluorescence maximum to illustrate differences in spectral shapes. The fluorescence maxima of $\mathrm{A} \beta_{1-40} \mathrm{WT}$ fibrils (485 nm), A $\beta_{1-40} \mathrm{WT}$ fibrils formed with $A \beta_{1-40}$ WT seeds (485 $\mathrm{nm}), \mathrm{A} \beta_{1-40} \mathrm{E} 22 \Delta$ fibrils (474 $\mathrm{nm}$ ) and $\mathrm{A} \beta_{1-40}$ WT initially seeded with $A \beta_{1-40}$ E22 $\Delta$ after up to 7 seeding/propagation cycles $(474 \mathrm{~nm})$ are indicated.

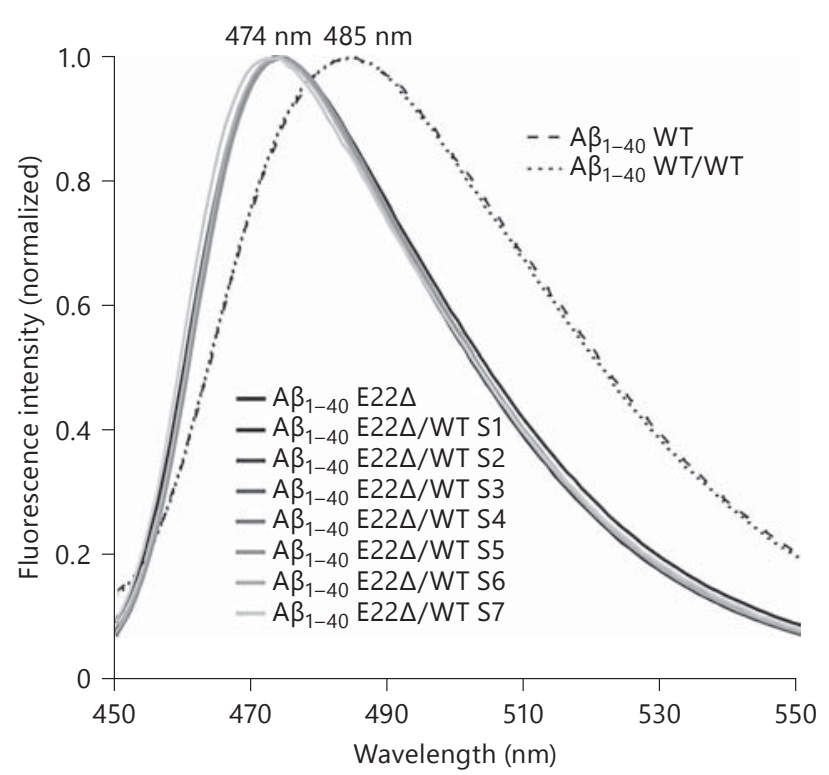

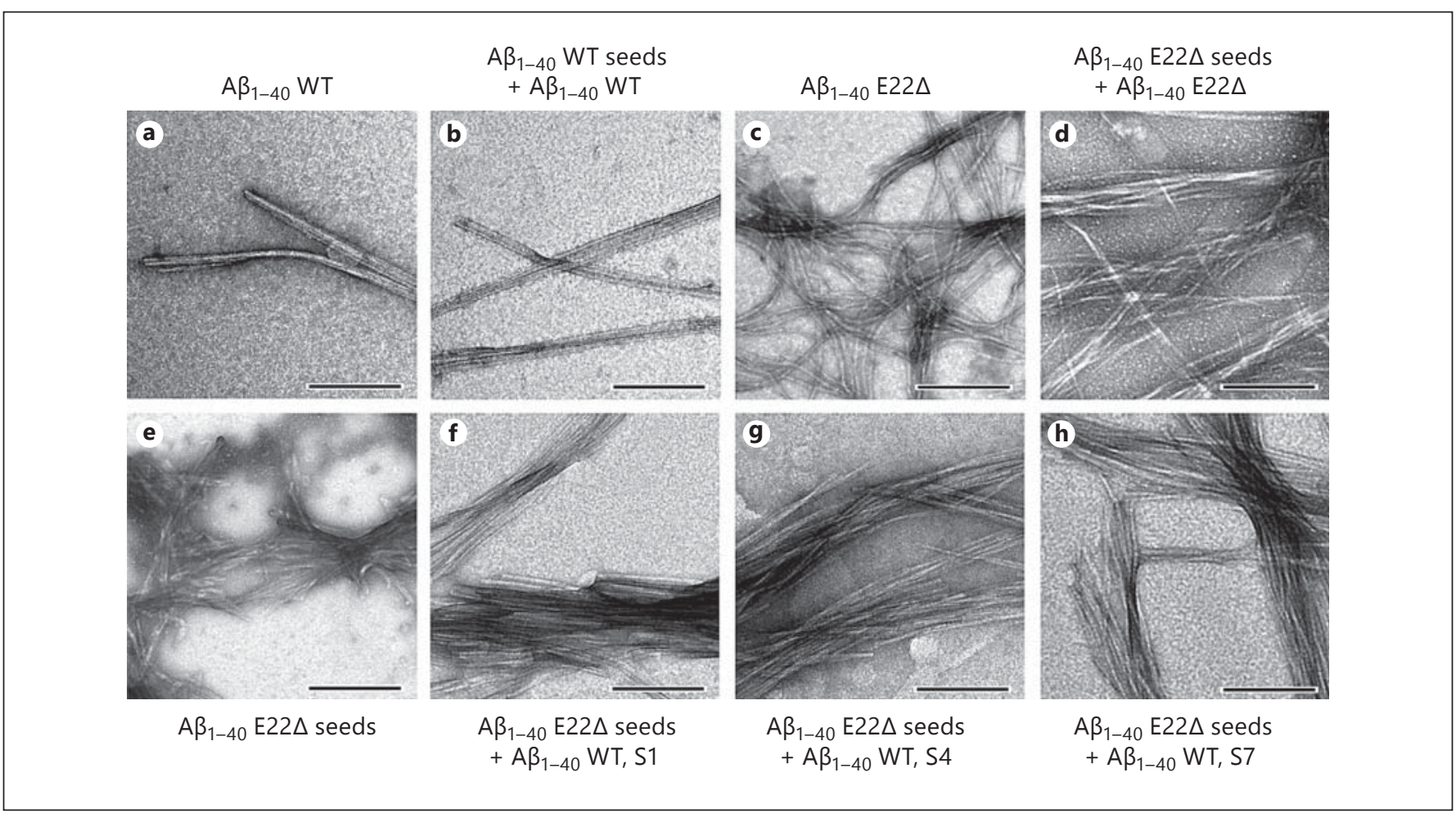

Fig. 3. Negatively stained electron micrographs of seeded and unseeded $\mathrm{A} \beta_{1-40}$ fibrils. Representative transmission electron microscopy images of fibrils formed from $\mathrm{A} \beta_{1-40} \mathrm{WT}(\mathbf{a}), \mathrm{A} \beta_{1-40} \mathrm{WT}$ in the presence of $\mathrm{A} \beta_{1-40}$ WT seeds (b), $A \beta_{1-40} \mathrm{E} 22 \Delta$ (c), $\mathrm{A} \beta_{1-40}$ E22 $\Delta$ in the presence of $A \beta_{1-40}$ E22 $\Delta$ seeds (d), A $\beta_{1-40}$ E22 $\Delta$ seeds after sonication (e), and $A \beta_{1-40}$ WT in the presence of $A \beta_{1-40} \mathrm{E} 22 \Delta$ seeds after 1 (f), 4 (g) and 7 (h) seeding cycles are shown (the seeding cycle numbers S1, S4 and S7 are indicated). The scale bars correspond to $100 \mathrm{~nm}$. 
Fig. 4. A model of fibril formation of $A \beta_{1-40}$ WT in the presence of $A \beta_{1-40} E 22 \Delta$ seeds. Spontaneously aggregating $\mathrm{A} \beta_{1-40} \mathrm{WT}$ (blue) and $\mathrm{A} \beta_{1-40} \mathrm{E} 22 \Delta$ (red) peptides form fibrils with distinct conformations. Monomeric $\mathrm{A} \beta_{1-40}$ WT incubated with seeds of sonicated $A \beta_{1-40} E 22 \Delta$ fibrils adopts the conformation of $A \beta_{1-40}$ E22 $\Delta$ fibrils and propagates it over several seeding cycles in a prion-like fashion.

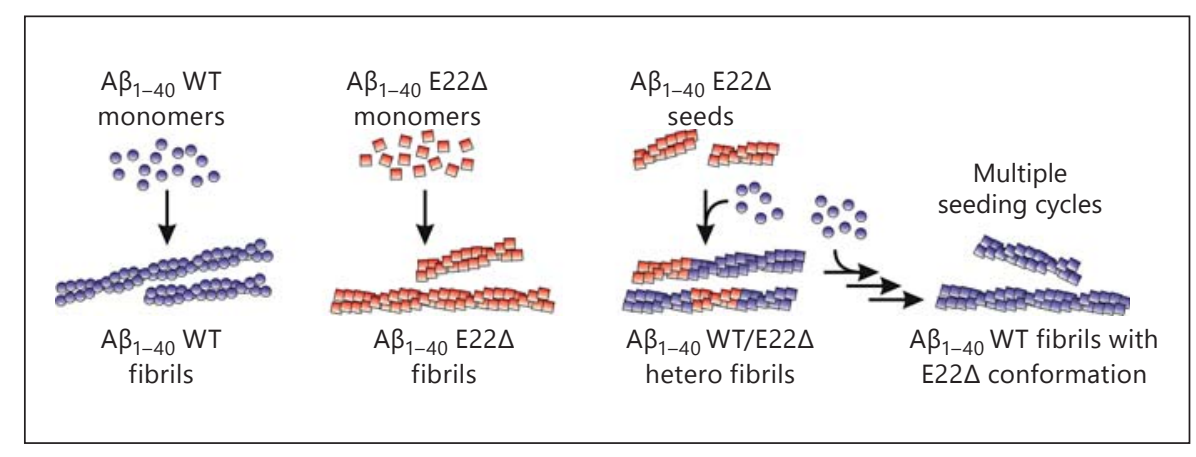

$\mathrm{A} \beta_{1-40}$ WT incubated in the absence of seeds as well as in the presence of $A \beta_{1-40}$ WT seeds mainly formed straight individual fibrils that laterally associated to discrete small bundles, while $A \beta_{1-40}$ E22 $\Delta$ fibrils displayed a high tendency to develop networks of fibrillar bundles, in agreement with earlier studies [12]. A $\beta_{1-40} \mathrm{WT}$ fibrils formed during multiple seeding/growth experiments that had initially been cross-seeded with $A \beta_{1-40}$ E22 $\Delta$ displayed morphologies very similar to the mutant form even after seven seeding cycles. Although less curved than $A \beta_{1-40}$ E22 $\Delta$ fibrils, these cross-seeded fibrils aggregated to extended networks of fibrillar bundles, which are clearly distinct from $\mathrm{A} \beta_{1-40} \mathrm{WT}$ fibrils. Fibrils formed during seeding cycles 1 through 7 were indistinguishable based on their fluorescence properties (fig. 3) and appearance in electron micrographs (data not shown).

After serial dilutions of the initial $A \beta_{1-40}$ E22 $\Delta$ seeds as a result of repetitive seeding and growth in the presence of $A \beta_{1-40} \mathrm{WT}$, only 1 molecule of $A \beta_{1-40}$ E22 $\Delta$ was present in the reaction mixture per 10 million molecules of $A \beta_{1-40}$ WT after cycle 7 . Thus, less than 1 in 1,000 fibrils still contains a single molecule of $A \beta_{1-40} E 22 \Delta$ after seven cycles of seeding, assuming that $A \beta_{1-40}$ fibrils with an average length of $1 \mu \mathrm{m}$ with mass-per-length values of $18-21 \mathrm{kDa} / \mathrm{nm}$ are formed (corresponding to an average of 4,000-5,000 A $\beta_{1-40}$ monomers per fibril) [20, 35, 40]. Therefore, although the vast majority of fibrils after seven seeding cycles are exclusively made up of $\mathrm{A} \beta_{1-40}$ WT molecules, these fibrils still retain the conformation of the initial A $\beta_{1-40}$ E22 $\Delta$ seeds (fig. 4). The results confirm a significant structural plasticity of $A \beta$ fibrils, highlight the ability of $A \beta$ fibrils to retain a specific quaternary structure under defined conditions of fibril propagation and demonstrate that $A \beta$ fulfills the molecular requirements for forming prion-like amyloid strains in $\mathrm{AD}$ patients.
Table 1. $C_{r}$ values and apparent free energies of fibril elongation $\left(\Delta \mathrm{G}^{\mathrm{app}}\right)$

\begin{tabular}{lrl}
\hline $\mathrm{A} \beta$ fibrils & $\mathrm{C}_{\mathrm{r}}, \mathrm{nM}$ & $\Delta \mathrm{G}^{\mathrm{app}}, \mathrm{kJ} / \mathrm{mol}$ \\
\hline $\mathrm{A} \beta_{1-40} \mathrm{WT}+\mathrm{A} \beta_{1-40} \mathrm{WT}$ seeds & $60 \pm 13$ & $-41.2 \pm 0.5$ \\
$\mathrm{~A} \beta_{1-40} \mathrm{E} 22 \Delta+\mathrm{A} \beta_{1-40} \mathrm{E} 22 \Delta$ seeds & $72 \pm 18$ & $-40.8 \pm 0.6$ \\
$\mathrm{~A} \beta_{1-40} \mathrm{WT}+\mathrm{A} \beta_{1-40} \mathrm{E} 22 \Delta$ seeds & $145 \pm 25$ & $-39.0 \pm 0.3$ \\
\hline
\end{tabular}

$\mathrm{C}_{\mathrm{r}}$ : Data are presented as means \pm standard deviations of 6 independent experiments performed in duplicate.

\section{Cross-Seeded Fibrils Are Thermodynamically}

Disfavored but Kinetically Stable

As proposed by Wetzel and coworkers [41], a comparison of fibril elongation thermodynamics, rather than the kinetics of fibril formation, was used to assess the effects of cross-seeding on $A \beta$ fibril formation. An $\mathrm{A} \beta_{1-40}$-specific ELISA was used to determine the concentrations of soluble monomers after the completion of fibrillization. This so-called critical concentration $\mathrm{C}_{\mathrm{r}}$ is formally equivalent to the dissociation constant of the monomer binding to the growing end of the fibril and can be used to compare thermodynamic stabilities of different fibrils $[16,38,39]$. The data in table 1 show that the homologously seeded $A \beta_{1-40}$ WT and $A \beta_{1-40}$ E22 $\Delta$ fibrils display similar residual monomer concentrations in the range of $60 \pm 13$ and $70 \pm 18 \mathrm{nM}$, respectively. $\mathrm{A} \beta_{1-40} \mathrm{WT}$ fibrils formed in the presence of $A \beta_{1-40}$ E22 $\Delta$ seeds displayed a significantly higher $C_{r}$ value of $145 \pm 25 \mathrm{~nm}$. The observed increase in $\mathrm{C}_{\mathrm{r}}$ corresponds to an apparent destabilization of the formed fibrils relative to $A \beta_{1-40}$ WT fibrils of $2.2 \mathrm{~kJ} / \mathrm{mol}$ through the imposed $A \beta_{1-40}$ E22 $\Delta$ fibril structure. Although thermodynamically disfavored, the cross-seeded $A \beta_{1-40}$ WT fibrils were kinetically stable and did not spontane- 
ously convert to the thermodynamically preferred $\mathrm{A} \beta_{1-40}$ WT conformation after $24 \mathrm{~h}$ of incubation, as evidenced by a constant, high ThT fluorescence signal of the cross-seeded fibrils (data not shown). De novo formation of nuclei with the more stable WT conformation may be suppressed by the low concentrations of free $A \beta_{1-40}$ monomers [42], and high activation energy barriers may prevent the direct interconversion between different fibril polymorphs due to the highly cooperative character of these reactions [22,43]. Under physiological conditions, $A \beta_{1-40}$ WT fibrils cross-seeded with $\mathrm{A} \beta_{1-40}$ E22 $\Delta$ nuclei may thus only convert back to the more stable WT conformation after an incubation period of several weeks or even much longer.

\section{Discussion}

Structural polymorphism and the ability of a specific fibrillar quaternary structure to propagate is not limited to yeast and mammalian prions. Previous studies with $\mathrm{A} \beta_{1-40}$, insulin and lysozyme showed that distinct amyloid conformations can be propagated in vitro through seeding and imply that prion-like strain behavior may be an inherent feature of proteinaceous amyloids $[11,34$, $35,44-46]$. However, the latter experiments were limited to one or two seeding cycles. The existence of polymorphic strains in $\mathrm{AD}$ with varying biological activities or even potentially infectious properties would require multiple, continuous seeding and elongation cycles, which have not been reported for $A \beta$. Using pure, recombinant $A \beta$ peptides, we analyzed cross-seeding of $A \beta_{1-40}$ WT monomers with preformed $A \beta_{1-40}$ E22 $\Delta$ seeds. Pronounced differences in their ThT fluorescence properties and distinct fibril morphologies demonstrated that $\mathrm{A} \beta_{1-40}$ WT can adopt the conformation of $\mathrm{A} \beta_{1-40} \mathrm{E} 22 \Delta$ fibrils and retain it over up to seven cycles of seeded polymerization. Our data thus provide direct evidence for the self-propagation of different $A \beta$ conformations and demonstrate that $A \beta$ possesses the basic property of forming amyloid strains in $\mathrm{AD}$, analogous to prion strains.

The $\beta$-sheet is the dominant, common structural feature of amyloid fibrils. However, structural models of $A \beta$ fibrils reported so far differ in the extent of $\beta$-sheet structure, and the exact positions of the $\beta$-strands in the $A \beta$ sequence vary in different structural models described for $\mathrm{A} \beta_{1-40}$ fibrils [35, 39, 47, 48]. The efficient seeding of $\mathrm{A} \beta_{1-40}$ WT by $\mathrm{A} \beta_{1-40}$ E22 $\Delta$ nuclei observed in our study suggests that position 22 is located in a turn region. An

Self-Propagation of A $\beta$ Fibril

Conformations amino acid deletion within a $\beta$-strand would flip all side chains of the following amino acid residues within this strand by $180^{\circ}$ from the outside to the interior of the fibril core and vice versa. The resulting conformational changes would be likely to prevent $A \beta_{1-40}$ E22 $\Delta$ to seed $A \beta_{1-40}$ WT peptides, as successful seeding relies on conformational complementarity between the seed fibril and the monomeric peptide associating with the growing fibril end. Our observations are consistent with simulation studies on the ensemble of monomeric $A \beta_{1-40}$, which indicate that the side chains of E22 and D23 remain exposed to the solvent [49].

In contrast to $A \beta_{1-40}$ WT seeded with $A \beta_{1-40}$ E22 $\Delta$ nuclei, $A \beta_{1-40}$ E22 $\Delta$ monomers were not efficiently crossseeded by $A \beta_{1-40}$ WT seeds. As proposed by Wetzel and coworkers [34] for $A \beta$ and islet amyloid polypeptide, a lack of reciprocity in cross-seeding might arise from different degrees of complementarity between the aggregation product and the seed. The missing residue in $A \beta_{1-40}$ E22 $\Delta$ might significantly decrease the conformational plasticity of this region and explain the failure to adopt the conformation of $A \beta_{1-40}$ WT fibrils. Alternatively, increased hydrophobicity due to the absence of the glutamate in $\mathrm{A} \beta_{1-40}$ E22 $\Delta$ might result in a higher amyloidogenic potential of this peptide. Using simulated free-energy profiles, Caflisch and coworkers [50] recently showed that fibril morphogenesis can switch from kinetic to thermodynamic control with increasing amyloidogenic potential, a scenario in which the $A \beta_{1-40}$ E22 $\Delta$ monomers would not be allowed to adopt an alternative, less stable conformation during cross-seeding.

Using a highly sensitive, quantitative ELISA assay, we determined critical monomer concentrations of $60 \pm 13$ and $70 \pm 18 \mathrm{nM}$ for homologously seeded $\mathrm{A} \beta_{1-40} \mathrm{WT}$ and $\mathrm{A} \beta_{1-40}$ E22 $\Delta$ fibrils, respectively. These values are in agreement with $C_{r}$ values recently determined by atomic force microscopy by Tycko and coworkers [42], but considerably lower than most previously reported $C_{r}$ values for $A \beta_{1-40}$ WT or $A \beta_{1-40} E 22 \Delta$, which range from 0.2 to $8 \mu \mathrm{M}[11,36,38,39,51-54]$. The low $\mathrm{C}_{\mathrm{r}}$ values observed in our study might be a consequence of the high purity of the recombinant $A \beta$ peptides used, which are likely to have yielded more homogeneous and more stable fibrils compared to fibrils formed by synthetic peptides. Our determined $C_{r}$ value for $A \beta_{1-40}$ may thus be a good estimate of the minimum $A \beta_{1-40}$ monomer concentration required for spontaneous fibril formation in vivo. $A \beta_{1-40}$ monomer levels in human brain extracellular fluids were indeed reported to be in the low nanomolar range [55-57]. 


\section{Acknowledgments}

We would like to thank Hiang Dreher-Teo for the purification of tobacco etch virus protease. We acknowledge Peter Tittmann (Electron Microscopy Center, ETH Zurich) for technical support and Serge Chesnov (Functional Genomics Center Zurich) for the acquisition of mass spectra. This work was funded by the ETH Zurich and the Swiss National Science Foundation within the framework of the program 'NCCR Neural Plasticity and Repair'.

\section{References}

1 Shastry BS: Neurodegenerative disorders of 14 Lomakin A, Chung DS, Benedek GB, protein aggregation. Neurochem Int 2003;43: $1-7$.

2 Carrell RW, Lomas DA: Conformational disease. Lancet 1997;350:134-138.

-3 Bucciantini M, Giannoni E, Chiti F, Baroni F, Formigli L, Zurdo J, Taddei N, Ramponi G, Dobson CM, Stefani M: Inherent toxicity of aggregates implies a common mechanism for protein misfolding diseases. Nature 2002;416: 507-511.

4 Caughey B, Lansbury PT: Protofibrils, pores, fibrils, and neurodegeneration: separating the responsible protein aggregates from the innocent bystanders. Annu Rev Neurosci 2003;26: 267-298.

-5 Guijarro JI, Sunde M, Jones JA, Campbell ID, Dobson CM: Amyloid fibril formation by an SH3 domain. Proc Natl Acad Sci USA 1998; 95:4224-4228.

6 Ohnishi S, Takano K: Amyloid fibrils from the viewpoint of protein folding. Cell Mol Life Sci 2004;61:511-524.

7 Goldschmidt L, Teng PK, Riek R, Eisenberg D: Identifying the amylome, proteins capable of forming amyloid-like fibrils. Proc Natl Acad Sci USA 2010;107:3487-3492.

8 Hardy J, Selkoe DJ: The amyloid hypothesis of Alzheimer's disease: progress and problems on the road to therapeutics. Science 2002;297: 353-356.

-9 Finder VH, Glockshuber R: Amyloid-beta aggregation. Neurodegener Dis 2007;4:13-27.

10 Tomiyama T, Nagata T, Shimada H, Teraoka R, Fukushima A, Kanemitsu H, Takuma H, Kuwano R, Imagawa M, Ataka S, Wada Y, Yoshioka E, Nishizaki T, Watanabe Y, Mori H: A new amyloid-beta variant favoring oligomerization in Alzheimer's-type dementia. Ann Neurol 2008;63:377-387.

-11 Cloe AL, Orgel JP, Sachleben JR, Tycko R, Meredith SC: The Japanese mutant $\mathrm{A} \beta(\Delta \mathrm{E} 22-$ $A \beta_{1-39}$ ) forms fibrils instantaneously, with low thioflavin T fluorescence: seeding of wildtype $A \beta_{1-40}$ into atypical fibrils by $\Delta E 22$ $\mathrm{A} \beta_{1-39}$. Biochemistry 2011;50:2026-2039.

12 Ovchinnikova OY, Finder VH, Vodopivec I, Nitsch RM, Glockshuber R: The Osaka FAD mutation E22 $\Delta$ leads to the formation of a previously unknown type of amyloid beta fibrils and modulates $\mathrm{A} \beta$ neurotoxicity. J Mol Biol 2011;408:780-791.

13 Jarrett JT, Lansbury PT Jr: Seeding 'one-dimensional crystallization' of amyloid: a pathogenic mechanism in Alzheimer's disease and scrapie? Cell 1993;73:1055-1058. Kirschner DA, Teplow DB: On the nucleation and growth of amyloid beta-protein fibrils: detection of nuclei and quantitation of rate constants. Proc Natl Acad Sci USA 1996;93: 1125-1129.

15 Lomakin A, Teplow DB, Kirschner DA, Benedek GB: Kinetic theory of fibrillogenesis of amyloid beta-protein. Proc Natl Acad Sci USA 1997;94:7942-7947.

16 Harper JD, Lansbury PT Jr: Models of amyloid seeding in Alzheimer's disease and scrapie: mechanistic truths and physiological consequences of the time-dependent solubility of amyloid proteins. Annu Rev Biochem 1997;66:385-407.

17 Tycko R: Progress towards a molecular-level structural understanding of amyloid fibrils. Curr Opin Struct Biol 2004;14:96-103.

$\checkmark 18$ Tycko R: Solid-state NMR studies of amyloid fibril structure. Annu Rev Phys Chem 2011; 62:279-299.

19 Fandrich M, Meinhardt J, Grigorieff N: Structural polymorphism of Alzheimer $\mathrm{A} \beta$ and other amyloid fibrils. Prion 2009;3:89-93.

20 Goldsbury C, Frey P, Olivieri V, Aebi U, Muller SA: Multiple assembly pathways underlie amyloid-beta fibril polymorphisms. J Mol Biol 2005;352:282-298.

21 Meinhardt J, Sachse C, Hortschansky P, Grigorieff N, Fandrich M: $A \beta_{1-40}$ fibril polymorphism implies diverse interaction patterns in amyloid fibrils. J Mol Biol 2009;386:869-877.

22 Paravastu AK, Leapman RD, Yau WM, Tycko R: Molecular structural basis for polymorphism in Alzheimer's beta-amyloid fibrils. Proc Natl Acad Sci USA 2008;105:18349-18354.

23 Prusiner SB: Molecular biology of prion diseases. Science 1991;252:1515-1522.

24 Jucker M, Walker LC: Self-propagation of pathogenic protein aggregates in neurodegenerative diseases. Nature 2013;501:45-51.

25 Riek R: Cell biology: infectious Alzheimer's disease? Nature 2006;444:429-431.

26 Prusiner SB: Cell biology. A unifying role for prions in neurodegenerative diseases. Science 2012;336:1511-1513.

27 Eisenberg D, Jucker M: The amyloid state of proteins in human diseases. Cell 2012;148: 1188-1203.

28 Eisele YS: From soluble A $\beta$ to progressive $A \beta$ aggregation: could prion-like templated misfolding play a role? Brain Pathol 2013;23:333341.

29 Kane MD, Lipinski WJ, Callahan MJ, Bian F, Durham RA, Schwarz RD, Roher AE, Walker
LC: Evidence for seeding of beta-amyloid by intracerebral infusion of Alzheimer brain extracts in beta-amyloid precursor protein-transgenic mice. J Neurosci 2000;20:3606-3611.

30 Meyer-Luehmann M, Coomaraswamy J, Bolmont T, Kaeser S, Schaefer C, Kilger E, Neuenschwander A, Abramowski D, Frey P, Jaton AL, Vigouret JM, Paganetti P, Walsh DM, Mathews PM, Ghiso J, Staufenbiel M, Walker LC, Jucker M: Exogenous induction of cerebral beta-amyloidogenesis is governed by agent and host. Science 2006;313:17811784.

-31 Stohr J, Watts JC, Mensinger ZL, Oehler A, Grillo SK, DeArmond SJ, Prusiner SB, Giles K: Purified and synthetic Alzheimer's amyloid beta $(A \beta)$ prions. Proc Natl Acad Sci USA 2012;109:11025-11030.

- 32 Heilbronner G, Eisele YS, Langer F, Kaeser SA, Novotny R, Nagarathinam A, Aslund A, Hammarstrom P, Nilsson KP, Jucker M: Seeded strain-like transmission of beta-amyloid morphotypes in APP transgenic mice. EMBO Rep 2013;14:1017-1022.

33 Lu JX, Qiang W, Yau WM, Schwieters CD, Meredith SC, Tycko R: Molecular structure of beta-amyloid fibrils in Alzheimer's disease brain tissue. Cell 2013;154:1257-1268.

- 34 O'Nuallain B, Williams AD, Westermark P, Wetzel R: Seeding specificity in amyloid growth induced by heterologous fibrils. J Biol Chem 2004;279:17490-17499.

- 35 Petkova AT, Leapman RD, Guo Z, Yau WM, Mattson MP, Tycko R: Self-propagating, molecular-level polymorphism in Alzheimer's beta-amyloid fibrils. Science 2005;307:262265.

36 Kodali R, Williams AD, Chemuru S, Wetzel $R: A \beta_{1-40}$ forms five distinct amyloid structures whose beta-sheet contents and fibril stabilities are correlated. J Mol Biol 2010;401: 503-517.

- 37 Finder VH, Vodopivec I, Nitsch RM, Glockshuber R: The recombinant amyloidbeta peptide $A \beta_{1-42}$ aggregates faster and is more neurotoxic than synthetic $A \beta_{1-42}$. J Mol Biol 2010;396:9-18.

38 O’Nuallain B, Shivaprasad S, Kheterpal I, Wetzel R: Thermodynamics of $A \beta_{1-40}$ amyloid fibril elongation. Biochemistry 2005;44: 12709-12718.

39 Williams AD, Portelius E, Kheterpal I, Guo JT, Cook KD, Xu Y, Wetzel R: Mapping A $\beta$ amyloid fibril secondary structure using scanning proline mutagenesis. J Mol Biol 2004; 335:833-842. 
40 Goldsbury CS, Wirtz S, Muller SA, Sunderji S, Wicki P, Aebi U, Frey P: Studies on the in vitro assembly of $A \beta_{1-40}$ : implications for the search for $A \beta$ fibril formation inhibitors. J Struct Biol 2000;130:217-231.

41 Williams AD, Shivaprasad S, Wetzel R: Alanine scanning mutagenesis of $A \beta_{1-40}$ amyloid fibril stability. J Mol Biol 2006;357:12831294.

42 Qiang W, Kelley K, Tycko R: Polymorph-specific kinetics and thermodynamics of betaamyloid fibril growth. J Am Chem Soc 2013; 135:6860-6871.

43 Dzwolak W, Grudzielanek S, Smirnovas V, Ravindra R, Nicolini C, Jansen R, Loksztejn A, Porowski S, Winter R: Ethanol-perturbed amyloidogenic self-assembly of insulin: looking for origins of amyloid strains. Biochemistry 2005;44:8948-8958.

-44 Paravastu AK, Qahwash I, Leapman RD, Meredith SC, Tycko R: Seeded growth of betaamyloid fibrils from Alzheimer's brain-derived fibrils produces a distinct fibril structure. Proc Natl Acad Sci USA 2009;106:74437448.

45 Dzwolak W, Smirnovas V, Jansen R, Winter $\mathrm{R}$ : Insulin forms amyloid in a strain-dependent manner: An FT-IR spectroscopic study. Protein Sci 2004;13:1927-1932.
46 Morozova-Roche LA, Zurdo J, Spencer A, Noppe W, Receveur V, Archer DB, Joniau M, Dobson CM: Amyloid fibril formation and seeding by wild-type human lysozyme and its disease-related mutational variants. J Struct Biol 2000;130:339-351.

47 Olofsson A, Lindhagen-Persson M, Sauer-Eriksson AE, Ohman A: Amide solvent protection analysis demonstrates that amyloid- $\beta_{1-40}$ and amyloid- $\beta_{1-42}$ form different fibrillar structures under identical conditions. Biochem J 2007;404:63-70.

48 Török M, Milton S, Kayed R, Wu P, McIntire T, Glabe CG, Langen R: Structural and dynamic features of Alzheimer's $A \beta$ peptide in amyloid fibrils studied by site-directed spin labeling. J Biol Chem 2002;277:40810-40815.

- 49 Vitalis A, Caflisch A: Micelle-like architecture of the monomer ensemble of Alzheimer's amyloid-beta peptide in aqueous solution and its implications for $\mathrm{A} \beta$ aggregation. J Mol Biol 2010;403:148-165.

50 Pellarin R, Schuetz P, Guarnera E, Caflisch A: Amyloid fibril polymorphism is under kinetic control. J Am Chem Soc 2010;132:1496014970.

51 Harper JD, Wong SS, Lieber CM, Lansbury PT Jr: Assembly of A $\beta$ amyloid protofibrils: an in vitro model for a possible early event in Alzheimer's disease. Biochemistry 1999;38: 8972-8980.

52 Doran TM, Anderson EA, Latchney SE, Opanashuk LA, Nilsson BL: Turn nucleation perturbs amyloid beta self-assembly and cytotoxicity. J Mol Biol 2012;421:315-328.
3 Inayathullah $\mathrm{M}$, Teplow DB: Structural dynamics of the $\Delta \mathrm{E} 22$ (Osaka) familial Alzheimer's disease-linked amyloid- $\beta$ protein. Amyloid 2011;18:98-107.

54 Hasegawa K, Ono K, Yamada M, Naiki H: Kinetic modeling and determination of reaction constants of Alzheimer's beta-amyloid fibril extension and dissociation using surface plasmon resonance. Biochemistry 2002; 41:13489-13498.

55 Kanai M, Matsubara E, Isoe K, Urakami K, Nakashima K, Arai H, Sasaki H, Abe K, Iwatsubo T, Kosaka T, Watanabe M, Tomidokoro Y, Shizuka M, Mizushima K, Nakamura T, Igeta Y, Ikeda Y, Amari M, Kawarabayashi T, Ishiguro K, Harigaya Y, Wakabayashi K, Okamoto K, Hirai S, Shoji M: Longitudinal study of cerebrospinal fluid levels of tau, $A \beta_{1-40}$, and $A \beta_{1-42(43)}$ in Alzheimer's disease: a study in Japan. Ann Neurol 1998;44:17-26.

56 Seubert P, Vigo-Pelfrey C, Esch F, Lee M, Dovey H, Davis D, Sinha S, Schlossmacher M, Whaley J, Swindlehurst C, et al: Isolation and quantification of soluble Alzheimer's betapeptide from biological fluids. Nature 1992; 359:325-327.

57 Schoonenboom NS, Mulder C, Van Kamp GJ, Mehta SP, Scheltens P, Blankenstein MA, Mehta PD: Amyloid beta 38, 40, and 42 species in cerebrospinal fluid: more of the same? Ann Neurol 2005;58:139-142. 